\title{
Conservation of forest based on a fuelwood substitute as well as considering the cultural and spiritual values: an optimal fuelwood harvest model
}

Polash Banerjee ( $\sim$ banerjee.polash@gmail.com )

Sikkim Manipal University

\section{Research Article}

Keywords: Fuelwood, Optimal Control Theory, Comparative Statics, Maximum Sustainable Yield, Open access forest

Posted Date: October 20th, 2020

DOI: https://doi.org/10.21203/rs.3.rs-93345/v1

License: (c) (i) This work is licensed under a Creative Commons Attribution 4.0 International License.

Read Full License 
2 Funding: None

3

4 Conflicts of interest/Competing interests: None

5

6 Availability of data and material: Yes

$7 \quad$ https://doi.org/10.6084/m9.figshare.8198801.v2

8

9 Authors' contributions: Planning, data gathering, data processing, modelling and interpretation.

10

11

12

13

14

15

16

17

18

19

20

21

22

23

24

25

26 
1 Conservation of forest based on a fuelwood substitute as well as considering the cultural and 2 spiritual values: an optimal fuelwood harvest model

Abstract

4 Excessive fuelwood harvest is a major cause of deforestation in the developing countries. To mitigate 5 this, various preventive measures have been introduced in different countries. Availability of affordable 6 substitute to the community dependent on the forest for domestic energy consumption may prevent 7 further forest degradation. A stock dependent optimal control model of fuelwood harvest from a natural 8 forest is presented here and comparative statics has been used to show that the presence of a fuelwood 9 substitute will reduce its harvest and increase the forest stock. The model indicates that availability of 10 cheaper and high energy content alternative for fuelwood can substantially reduce fuelwood extraction 11 from a forest. Also, a lower discount rate and higher cultural and spiritual values (CSV) will keep the 12 optimal forest stock close to its carrying capacity and reduce fuelwood harvest. The model reveals that 13 the maximum sustainable yield of forest stock and the ratio of energy content per unit mass of fuel play 14 a central role in the fate of forest stock and level of fuelwood harvest. Empirical example of the 15 Southeast Asian forest growth model along with Liquid Petroleum Gas (LPG) as substitute has been 16 used to illustrate the results. The outcomes of this study can incorporated into forest conservation 17 polices.

\section{Keywords}

19 Fuelwood; Optimal Control Theory; Comparative Statics; Maximum Sustainable Yield; Open access 20 forest

21 Abbreviations

Cultural and Spiritual Values

CSV

Marginal Rate of Substitution

MRS

\section{Introduction}

Forest plays a central role in meeting the social and economic needs of the people living in its vicinity. Along with timber, forest provides Non-Timber Forest Products (NTFP) like fuelwood, fodder and medicinal plants to these people. Also, people through their cultural and spiritual values (CSV) are aware of the socioecological functions played by the forest (Daniel et al., 2012; Laird, 1999).

A lot of literature has been devoted in understanding the impact of timber harvesting on the size and health of forest stock (Amacher, Ollikainen, \& Koskela, 2009; Faustmann, 1849; Hartman, 1976). However, in the developing countries, one of the major reasons for deforestation is excessive fuelwood extraction (Pattanayak, Sills, \& Kramer, 2004; Thierry Lefevre, Jessie L. Todoc, 1997; Troncoso, Castillo, Masera, \& Merino, 2007). For instance, fuelwood constitutes $76.3 \%$ and Liquid Petroleum Gas (LPG) only $11.5 \%$ of the energy mix in Indian rural households (National Sample Survey 
1 Organization (NSSO), 2012). Much of this dependence on fuelwood comes from the tribal and poor communities living in the proximity of forests. Also, increase in the population and lack of appropriate and affordable energy options and the very nature of the state-owned natural forests as an open access land resource have aggravated the situation (Heltberg, Arndt, \& Sekhar, 2000; Jagger \& Kittner, 2017).

5 Fuelwood extraction induced deforestation has several ecological consequences viz. loss of 6 biodiversity, deterioration of watershed, soil erosion and release of carbon dioxide into the atmosphere 7 (Brown et al., 2009; Pandey, 2002).

8 Several factors determine the per capita fuelwood consumption viz. household income, availability of 9 alternatives to fuelwood, use of efficient cooking/heating equipment, proximity to forest and climatic 10 conditions. However, in recent times increase in the income of households has facilitated switching 11 from fuelwood to relatively cleaner and convenient energy options like LPG and Biogas, provided such 12 options are readily available (Pandey, 2002). Studies in developing countries have shown that 13 appropriate fuelwood substitutes or efficient use of fuelwood can prevent deforestation (Adhikari, 2002; 14 Agarwala et al., 2017; Roy, 2008). Thereby, understanding the role of fuelwood extraction on the forest 15 stock and determinants of fuelwood harvesting remains an essential question for sustainable policy 16 decision making. Moreover, the role of non-monetary forest values like cultural and spiritual values 17 (CSV) on the forest health needs further studies (Agnoletti \& Santoro, 2015; Lowman \& Sinu, 2017; 18 Torres, Morsello, Parry, \& Pardini, 2016). Often forest-dependent communities in developing countries 19 have religious, taboo and myth-based forest values that can be captured by CSV. Considering fuelwood 20 substitutes and CSV into forest conservation policies together may have better outcomes than otherwise.

21 Several modelling techniques have been used to evaluate the multifunctional role of forest (including 22 fuelwood harvest) in meeting the socioeconomic needs of the communities' dependent on it. Utility 23 maximization model has been used for the analysis of household production, consumption and substitution of fuelwood (Joshee, Amacher, \& Hyde, 2000). However, the study ignores the importance of dynamic nature of forest and focuses on static utility model. Role of socioeconomic and physical factors and the interaction of these factors on the forest regime have been analysed using optimal control theory (Kant, 2000). Impacts of non-timber valuation on the forest stock and timber harvest have been analysed using optimal control theory and comparative statics (Gan, Kolison, \& Colletti, 2001). Discrete optimal control model has been used to evaluate the role of fuelwood burning on the climate (Lyon, 2004). Dynamic optimization techniques have been used to model the non-timber forest extraction in spatio-temporal context (Robinson, Albers, \& Williams, 2008). Dynamic system modelling based study indicates that fuelwood harvesting causes forest degradation, forest fire, institutional failure and socioecological problems to the forest-dependent communities (Ranjan, 2018). Majority of these studies consider fuelwood under the broad heading of non-timber benefits and do not exclusively analyze the impact of fuelwood extraction on the forest stock and harvest decision. Also, role of consumer's choice between fuelwood and its substitute on the forest stock and harvest decision has not been studied using optimal control theory and comparative statics. Moreover, conventionally forest growth is considered as the function of time. Such considerations are appropriate when the forest is private property and objective of the owner is to harvest timber at an optimal rotation period (Amacher et al., 2009). Such an approach is not appropriate for open access resources like a large natural forest with uneven age classes and multiple uses. Thereby, a more appropriate determinant for harvest decision should be forest stock size rather than time.

This article considers a present value maximization problem where the households living in the vicinity of an open-access natural forest are to maximize their CSV and utility of fuelwood harvest in the presence of a substitute. Optimal control theory is used to analyse the role of discount rate, CSV 
1 function, marginal utility of fuelwood (MUF) and marginal utility of substitute (MUS) on the marginal 2 forest growth. Also, comparative statics is used to evaluate the impact of marginal change in discount 3 rate and CSV, marginal utility of fuelwood and substitute on the optimal forest stock and optimal 4 fuelwood harvest. An empirical example of the impacts of fuelwood harvest in the presence of a 5 substitute on the biomass stock of the Southeast Asian forest has been used to illustrate the theoretical 6 results. The outcomes of this model can be generalised to all forms of forest wood products and forest 7 values other than CSV.

\section{2. Methodology and theoretical approach}

9 In the present model, the households living in the vicinity of the state-owned open-access natural forest 10 and access the forest fuelwood for domestic purposes are considered as the consumers. The consumers, 11 along with fuelwood also reap forest benefits in the form of timber and other NTFP. Moreover, 12 consumers have a system of CSV that encourages forest conservation. This model is an extension of 13 the work of Gen et al. (2001), incorporating the role of non-monetary forest values and fuelwood 14 substitutes on exploitation of wood products, like fuelwood, from the open-access forests in developing 15 countries.

\section{2.1. The model}

17 The objective of the consumer is to maximize his utility, $U($.$) and the CSV, V($.$) by selecting the$ 18 optimal rate of fuelwood harvest, $h(t)$ subject to various constraints given below:

$19 P: \max _{h} \int_{0}^{\infty}[U(h(t), s(t))+V(x(t))] e^{-\delta t}$

20 Subject to:

$21 \quad \frac{d x}{d t}=g(x(t))-h(t)$

$22 x(0)=x_{0}$

$23 x(t) \geq 0$

$24 s(t) \geq 0$

$0 \leq h(t) \leq h_{\max }$

$d=p h(t)+\rho s(t)$

27 Where, the forest stock, $x(t)$ follows a quasiconcave growth function, $g(x(t))$ such as logistic growth 28 function (Amacher et al., 2009; Gan et al., 2001). The instantaneous forest growth, $\frac{d x}{d t}$ is a function of 29 its growth function, $g(x(t))$ and fuelwood harvest, $h(t) . h_{\max }$ is the maximum fuelwood harvest rate 30 defined by the availability of capital and labour for extraction of fuelwood. The utility function, $U($.$) is$ 31 a quasiconcave function over fuelwood harvest, $h(t)$ and its substitute, $s(t)$. The daily domestic energy 32 demand, $d$ is the sum of the product of fuelwood harvest, $h(t)$ and its energy content per unit biomass, $33 p$ and the product level of consumption of its substitute, $s(t)$ and the energy content of the substitute 34 per unit mass, $\rho$. 
1 The following assumptions are made for the convenience of the model:

2 1. $g_{x}\left\{\begin{array}{l}>0, \text { when } x<x_{m s y} \\ =0, \text { when } x=x_{m s y} \\ <0, \text { when } x>x_{m s y}\end{array}\right.$ and $g_{x x}<0$

3 2. $V_{x}>0$, when $V_{x x}<0$

$4 \quad 3 . U_{h}>0$, when $U_{h h}<0$

5 4. $U_{s}>0$, when $U_{s s}<0$

6 Where, $g_{x}=\frac{\partial g}{\partial x}$ and $g_{x x}=\frac{\partial}{\partial x} \frac{\partial g}{\partial x}$ and so on, are partial derivatives. Assumption (1) states that there 7 exists a forest stock size, $x_{m s y}$ called Maximum Sustainable Yield (MSY) stock, below which the 8 marginal forest growth increases while above this value the marginal forest growth decreases. The 9 marginal forest growth is zero when forest stock is at MSY stock size. Marginal change in the marginal 10 forest growth is negative. Similarly, assumptions (2), (3) and (4) state that, CSV function, MUF and 11 MUS are increasing functions over their variables and their rate of increase is decreasing over their 12 variables respectively.

\section{2.2. Analysis of the model}

14 The current-value Hamiltonian corresponding to equation (1) is given by:

$H(x(t), h(t), \mu(t))=U(h(t), s(t))+V(x(t))+\mu(t)[g(x(t))-h(t)]$

16 where, $\mu(t)=\lambda e^{\delta t} ; \lambda$ is the adjoint variable, $\delta$ is the discount rate, $t$ is the time and $\mu(t)$ is the 17 shadow price of the forest growth function. The shadow price captures the non-market value of the 18 forest in the form of ecological, cultural, spiritual, health and to some extent recreational services 19 provided by the forest. Substituting $s(t)$ in $U($.$) by rearranging equation (7), modifies the utility$ 20 function as:

$21 U(h(t), s(t))=U\left(h(t), \frac{d}{\rho}-\kappa h(t)\right)$

22 Where $\kappa=\frac{\rho}{p}$, is the ratio of energy content per unit mass of the substitute to that of fuelwood. The 23 first order condition of $H($.$) , as given in equation (8), is given by:$

$24 \quad \frac{\partial H}{\partial h}=U_{h}-\kappa U_{s}-\mu=0$

$25-\frac{\partial H}{\partial x}=-V_{x}-\mu g_{x}=\frac{d \mu}{d t}-\delta \mu$

26 Rearranging equations (10) and (11) give:

$27 \mu(t)=U_{h}-\kappa U_{s}$

$28 \quad \frac{d \mu}{d t}=\left(\delta-g_{x}\right) \mu(t)-V_{x}$

29 Equation (12) suggest that at optimal utility level the shadow price of the forest stock is equal to the 30 difference between, $\kappa$ th-times the MUS from the MUF. Equations (2), (3), (12) and (13) along with 
1 inequations (4) to (6), constitute a simultaneous equation system. By setting $\frac{d x}{d t}=\frac{d h}{d t}=0$, we can solve 2 for the optimal steady state solution, $\left(x^{*}, h^{*}\right)$. If the forest stock is not at its optimal stock level, then 3 the fuelwood harvest decision can follow any of the two optimal paths. These are the Asymptotic 4 Approach Path or the Most Rapid Approach Path (MRAP), to reach the optimal forest stock (Clark, 5 1990). As per the MRAP or 'Bang-Bang' control approach, the optimal harvest, $h^{*}$ is:

$6 \quad h^{*}=\left\{\begin{array}{cc}h_{\max }, & \text { when } x>x^{*} \\ g\left(x^{*}\right), & \text { when } x(t)=x^{*} \\ 0, & \text { when } x(t)<x^{*}\end{array}\right.$

7 Equation (14) suggests that the optimal harvest is equal to the maximum harvest rate whenever the 8 forest stock is above the optimal forest stock. At sub-optimal forest stock level, fuelwood harvest is not 9 appropriate. Lastly, under optimal forest stock condition fuelwood harvest rate equals the natural 10 growth rate of the forest.

\section{3. Results}

\section{3.1. Effect of fuelwood harvest on forest stock}

13 Total differentiation of equation (12), equating it with equation (13) and setting $\frac{d h}{d t}=0$ gives:

$14\left(\delta-g_{x}\right)\left(U_{h}-\kappa U_{s}\right)-V_{x}=0$

15 Rearranging equation (15) gives discount rate as:

$16 \delta=g_{x}+\frac{V_{x}}{U_{h}-\kappa U_{s}}$

17 Equation (16) establishes the relationship of discount rate with the marginal growth of forest stock, $g_{x}$, 18 marginal growth of CSV, $V_{x}$, MUF and MUS. In the absence of CSV, $V_{x}=0$ :

$19 \delta=g_{x}$

20 Equation (17) implies that, in the absence of CSV, in order to maximize the fuelwood harvest under 21 steady state condition, the marginal forest growth should be equal to the discount rate. Since, $g(x(t))$ 22 is a quasiconcave function, there exists a relation between optimal forest stock and MSY:

$\left.23 \quad \begin{array}{lll}x^{*}>x_{m s y} & , \text { causes } & g_{x}<0 \\ x^{*}=x_{m s y} & , \text { causes } & g_{x}=0 \\ x^{*}<x_{m s y} & , \text { causes } & g_{x}>0\end{array}\right\}$

24 Equation (18) implies that, depending on the nature of the marginal forest growth function, the optimal 25 forest stock will be below, equal to or above the MSY of the forest (Gan et al., 2001). Moreover, as:

$\delta \rightarrow 0, g_{x} \rightarrow 0 \Longrightarrow x^{*} \rightarrow x_{m s y}$

27 The limiting condition (19) implies that, as the discount rate approaches zero, the marginal forest growth 28 also approaches zero. From equation (18), this change suggests that as the forest growth rate approaches 29 zero, the optimal forest stock approaches MSY stock size. 
1 In the absence of MUF, equation (16) is expressed as:

$2 \delta=g_{x}-\frac{V_{x}}{k U_{s}}$

3 Equation (20) implies that in the absence of MUF the discount rate is less than the marginal forest 4 growth by a factor equal to the ratio of marginal change in CSV to $\kappa$-times the MUS. In the absence of 5 fuelwood harvest, the lowered discount rate will help in conserving the forest. In the absence of MUS, $6 U_{s}=0$, equation (16) is expressed as (Gan et al., 2001):

$7 \quad \delta=g_{x}+\frac{V_{x}}{U_{h}}$

8 Equation (21) implies that in the absence of MUS the discount rate is more than the marginal forest 9 growth by a fraction equal to the ratio of marginal growth of CSV to the MUF. Comparing equation 10 (21) with equation (17) we observe that, in the absence of a substitute, even after considering CSV, the 11 MUF pushes the discount rate above the marginal forest growth, leading to exploitation of the forest for 12 fuelwood, timber and NTFP. Rearranging equation (16) gives:

$13 g_{x}=\delta-\frac{V_{x}}{U_{h}-\kappa U_{s}}$

14 Equation (23) suggests that at equilibrium the marginal forest growth, $g_{x}$ could be positive, negative or 15 zero.

16 Case I: if $\delta=0$ or $\delta<\frac{V_{x}}{U_{h}-\kappa U_{S}}$, then $g_{x}<0$, indicating that the optimal forest stock has exceeded the 17 MSY stock size. Such a situation will prevail if $\frac{U_{h}}{U_{S}}>\kappa$. Under such circumstances, the optimal forest 18 stock will be above MSY stock. This will cause the utility maximizing consumer to harvest fuelwood 19 using the MRAP strategy as given in equation (14).

20 Case II: if $\delta=\frac{V_{x}}{U_{h}-\kappa U_{S}}$ then $g_{x}=0$, indicating that the optimal forest stock is equal to the MSY stock 21 size and harvest rate is equal to MSY.

22 Case III: if $\delta>\frac{V_{x}}{U_{h}-\kappa U_{s}}$ or $\frac{U_{h}}{U_{s}}<\kappa$ then $g_{x}>0$. Under such circumstances, the optimal forest stock will 23 be below MSY stock size. This will cause the consumer to harvest fuelwood using the MRAP strategy 24 as given in equation (14) and will discourage further fuelwood harvest.

\section{3.2. Effect of model parameters on optimal forest stock and optimal harvest}

26 At equilibrium, let us consider that $V_{x}, U_{h}$ and $U_{s}$ approaches certain steady state values. Hence, let $V_{x}=$ $27 \varphi, U_{h}=\alpha$ and $U_{s}=\beta$. Then equation (16) is accordingly modified to:

$28 \delta=g_{x}+\frac{\varphi}{\alpha-\kappa \beta}$

29 Total differentiation of equation (25) and equation (2) at $\frac{d x}{d t}=0$, constitute a simultaneous equation 30 system: 
$1 \quad\left(\begin{array}{cc}g_{x} & -1 \\ g_{x x} & 0\end{array}\right)\left(\begin{array}{l}d x \\ d h\end{array}\right)=\left(\begin{array}{c}0 \\ d \delta-\frac{(\alpha-\kappa \beta) d \varphi-\varphi(d \alpha-\kappa d \beta)}{(\alpha-\kappa \beta)^{2}}\end{array}\right)$

\section{$2 \quad 3.2 .1$. Effect of discount rate}

3 Comparative statics is used to analyze the effect of changes in discount rate alone on the optimal forest

4 stock and optimal harvest, by letting $d \varphi=d \alpha=d \beta=0$ in equation (26). Also, let

$5 \quad \boldsymbol{A}=\left(\begin{array}{cc}g_{x} & -1 \\ g_{x x} & 0\end{array}\right)$

6 Thus, $|A|=g_{x x}<0 \Longrightarrow|A| \neq 0$. Hence, equation (26) is solved using Cremer's rule:

$7 \quad \frac{\partial x^{*}}{\partial \delta}=\frac{1}{g_{x x}}<0$

8 And,

$9 \quad \frac{\partial h^{*}}{\partial \delta}=\frac{g_{x}}{g_{x x}}\left\{\begin{array}{l}>0, x<x_{m s y} \\ =0, x=x_{m s y} \\ <0, x>x_{m s y}\end{array}\right.$

10 Considering assumption (1), equation (28) suggests that, increase in discount rate will encourage 11 deforestation. On the other hand, equation (29) implies that the optimal harvest increases with increase 12 in discount rate when forest stock is below MSY stock, while it decreases when forest stock is above

13 MSY stock and optimal harvest is not affected by the change in discount rate when forest stock equals 14 MSY stock.

\section{$15 \quad$ 3.2.2. Effect of CSV}

16 Considering, $d \delta=d \alpha=d \beta=0$, in equation (26) and solving:

$17 \frac{\partial x^{*}}{\partial \varphi}=-\frac{1}{(\alpha-\kappa \beta) g_{x x}}\left\{\begin{array}{c}<0, \frac{\alpha}{\beta}<\kappa \\ N . D^{1}, \frac{\alpha}{\beta}=\kappa \\ >0, \frac{\alpha}{\beta}>\kappa\end{array}\right.$

18 And,

$19 \quad \frac{\partial h^{*}}{\partial \varphi}=-\frac{g_{x}}{(\alpha-\kappa \beta) g_{x x}}$

20 From equation (30) it is observed that the optimal forest stock decreases with increase in CSV when the 21 MRS is below the ratio of energy value per unit mass of fuelwood to its substitute $(\kappa)$. In contrast, 22 optimal forest stock increases when MRS is above $\kappa$. The condition is unknown when MRS is equal to $23 \kappa$. Table (1), shows the possible outcomes of equation (31). If the MRS is below $\kappa$, the optimal harvest 24 increases, remains unaffected or decreases with increase in CSV when marginal forest growth is 25 negative, zero or positive respectively. If MRS is above $\kappa$, the optimal harvest decreases, remains

\footnotetext{
${ }^{1}$ N.D means Not Defined.
} 
1 unaffected or increases with increase in CSV when marginal forest growth is negative, zero or positive 2 respectively. There is no solution for change in the optimal harvest of fuelwood with change in CSV 3 when MRS equals $\kappa$.

4 Table 1: Changes in the sign of $\frac{\partial h^{*}}{\partial \varphi}$ with change in $g_{x}$ and value of $\frac{\alpha}{\beta}$ as compared to $\kappa$

\begin{tabular}{|c|c|c|c|}
\hline$\frac{\alpha}{\beta} g_{x}$ & $<0$ & $=0$ & $>0$ \\
\hline$<\kappa$ & & & $<0$ \\
\hline$=\kappa$ & $>0$ & $=0$ & $N . D$ \\
\hline$>\kappa$ & $N . D$ & $N . D$ & $>0$ \\
\hline
\end{tabular}

\section{$5 \quad 3.2 .3$. Effect of marginal utility of fuelwood}

6 Considering $d \delta=d \varphi=d \beta=0$, in equation (26) and solving:

$7 \quad \frac{\partial x^{*}}{\partial \alpha}=\frac{\varphi}{(\alpha-\kappa \beta)^{2} g_{x x}}<0$

8 And,

$9 \quad \frac{\partial h^{*}}{\partial \alpha}=\frac{\varphi g_{x}}{(\alpha-\kappa \beta)^{2} g_{x x}}\left\{\begin{array}{l}>0, x<x_{m s y} \\ =0, x=x_{m s y} \\ <0, x>x_{m s y}\end{array}\right.$

10 Equation (32) suggests that the optimal forest stock decreases with increase in MUF. Equation (33)

11 implies that the optimal harvest increases with increase in MUF when forest stock is below MSY stock

12 and decreases when forest stock is above MSY stock. The optimal harvest remains unaffected by the

13 change in MUF when forest stock equals the MSY stock.

\section{$14 \quad 3.2 .4$. Effect of marginal utility of substitute}

15 Considering $d \delta=d \varphi=d \alpha=0$, in equation (26) and solving gives:

$16 \quad \frac{\partial x^{*}}{\partial \beta}=-\frac{\varphi}{(\alpha-\kappa \beta)^{2} g_{x x}}>0$

17 And,

18

$$
\frac{\partial h^{*}}{\partial \beta}=-\frac{\varphi g_{x}}{(\alpha-\kappa \beta)^{2} g_{x x}}\left\{\begin{array}{l}
<0, x<x_{m s y} \\
=0, x=x_{m s y} \\
>0, x>x_{m s y}
\end{array}\right.
$$

19 Equation (34) suggests that the optimal forest stock increases with increase in marginal utility of 20 substitute. Equation (35) implies that the optimal harvest decreases with increase in MUS when forest 21 stock is below MSY stock and increases when forest stock is above MSY stock. The optimal harvest remains unaffected by the change in MUS when forest stock equals the MSY stock. 
1 The theoretical model discussed above requires further illustration using an empirical model. For this, 2 the Southeast Asian forest model was considered, as it fits the scenario of forest conditions prevalent in 3 developing countries (Figure 1) (Kallio, Dykstra, \& Binkley, 1987):

$4 \quad g(x)=\frac{d x}{d t}=b_{0} x-b_{1} x^{2}$

5 where, $b_{0}=r$, the biotic potential of the forest, $b_{1}=\frac{r}{K}$, and $K$ is the carrying capacity. According to 6 this model the natural regenerative growth of the forest, $b_{0} x$ is restricted by the interspecific 7 competition, $b_{1} x^{2}$ leading to a sigmoidal growth of forest biomass. The $\left(b_{0}, b_{1}\right)$ of Southeast Asian 8 forest is $(0.035,0.000136)$. Equation (36) is a logistic equation which is strictly quasiconcave and meets 9 the need of the model discussed here (Figure 1).

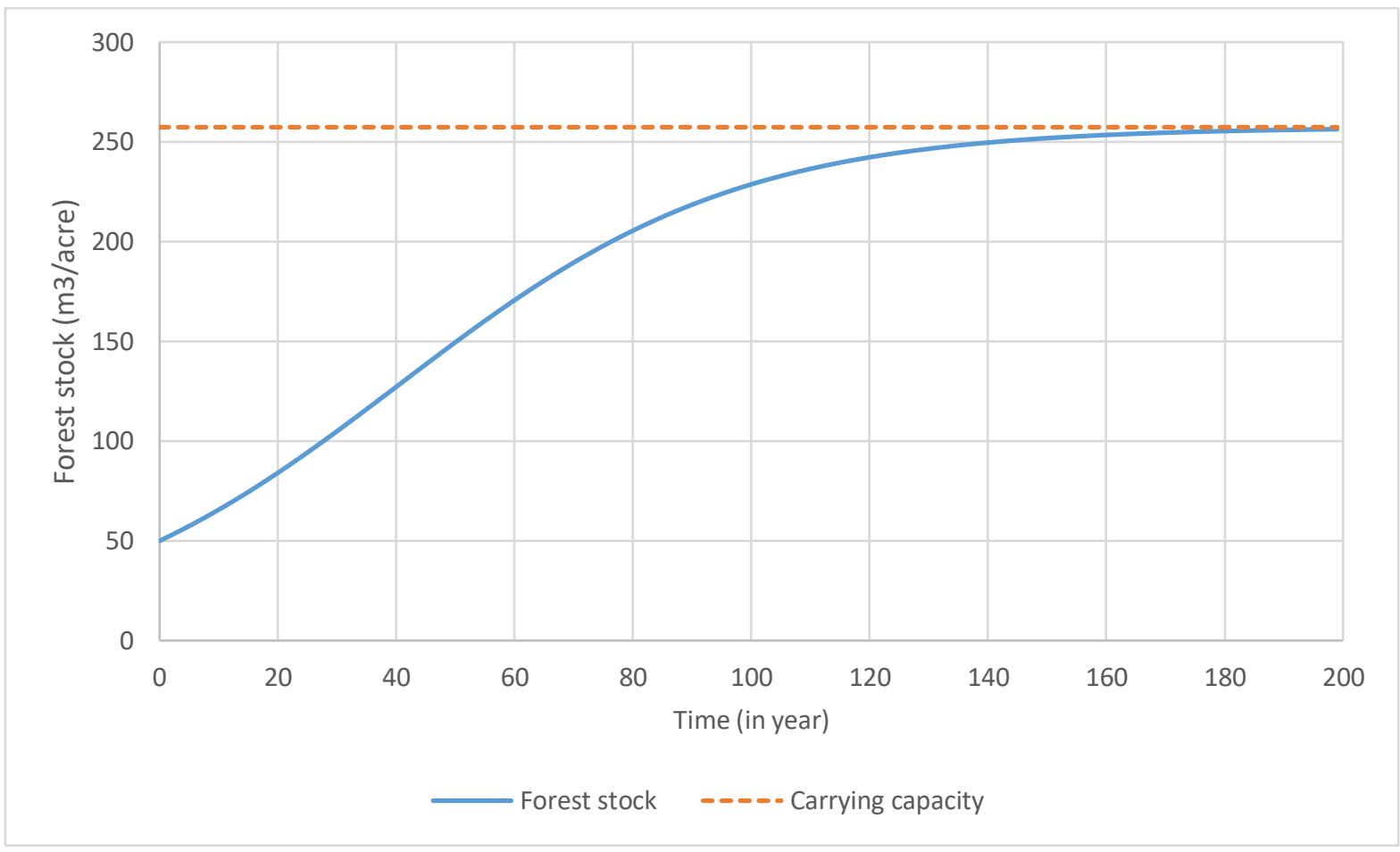

11 Figure 1: Logistic growth models of the Southeast Asian forest expressed by the relation $x_{t}=$ $12 \frac{x_{0} K}{x_{0}+\left(K-x_{0}\right) e^{-r t}}$, where $x_{0}$ is the initial forest biomass stock, $K$ is the carrying capacity, $r$ is the biotic 13 potential and $t$ is the time in years.

14 Let us assume that, $V_{x}=\varphi, U_{h}=\alpha$ and $U_{s}=\beta$, under optimum conditions where, $\alpha=\{10,20,30,40,50,60,70,80,90\}$, $\beta=\{90,80,70,60,50,40,30,20,10\}$,

$17 \varphi=\{0,2,4,6,8,10,12\}$, $\delta=\{0,2,4,6,8,10\}$

19 thereby, ${ }^{\alpha} / \beta=\{0.111,0.250,0.429,0.667,1,1.5,2.333,4,9\}$ are the MRS values considered. 20 Using equations (2), (4), (5), (12), (13) and (36) the optimal forest stock, $x^{*}$ and optimal harvest, $h^{*}$ are 
given as:

$2 \quad x^{*}=\frac{1}{2 b_{1}}\left(\frac{\varphi}{\alpha-\kappa \beta}-\delta+b_{0}\right)$

$3 \quad h^{*}=\frac{x^{*}}{2 b_{1}}\left(b_{0}-\frac{1}{2} x^{*}\right)$

4 The value of $\kappa$ is the ratio of the energy content of forest biomass to substitute. The value of $\kappa$ was 5 considered, based on the energy content of substitutes like LPG $(=46.1 \mathrm{MJ} / \mathrm{kg})$ and fuelwood of tropical 6 trees (= 20.90 MJ/kg) (Bauer, 1996; Duruaku, Ajiwe, Okoye, \& Arinze, 2016; Spîrchez, Lunguleasa, 7 \& Croitoru, 2017). $\kappa$ value for fuelwood to LPG was estimated as 0.453. A similar empirical analysis 8 was done using Southeast Asian forest model and Biogas. The outcomes of the analysis yielded similar 9 results as in case of Southeast Asian forest model and LPG. Using equations (39) and (40), the effect 10 of MRS of fuelwood by LPG, under various levels of CSV and discount rates on optimal harvest and optimal forest stock of the forest model was estimated (figure 2). The figure suggests how much to harvest in the long run for one acre of the forest at a given discount rate and MRS for a specific CSV.

13 Based on the values of $\left(b_{0}, b_{1}\right)$ the carrying capacity of Southeast Asian forest was estimated as $14257.353 \mathrm{~m}^{3} /$ acre. Considering $K / 2$ as the MSY stock, the MSY stock and MSY for Southeast Asian forest were estimated as $128.676 \mathrm{~m}^{3} /$ acre and $2.252 \mathrm{~m}^{3} /$ acre/year, respectively.

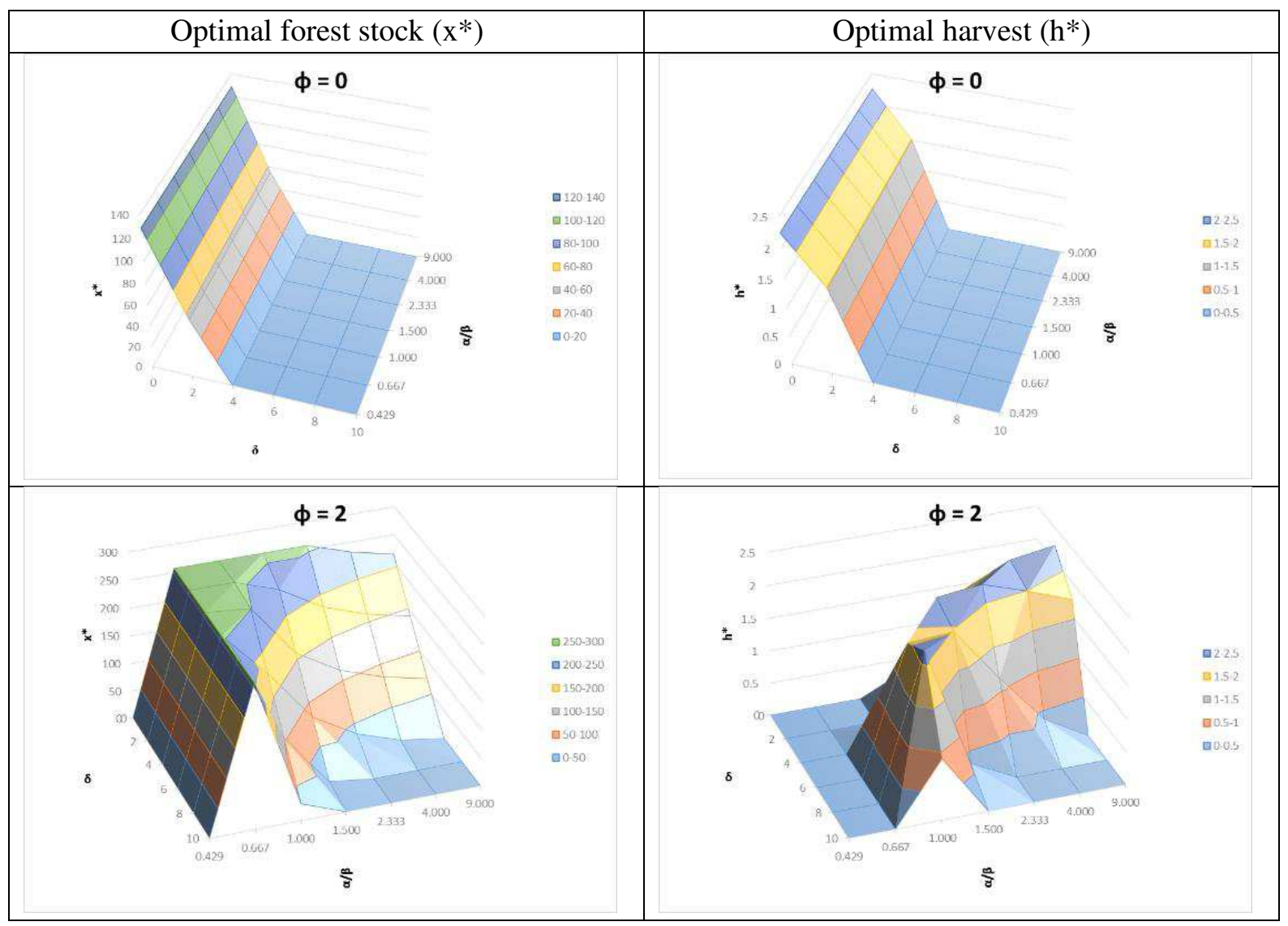




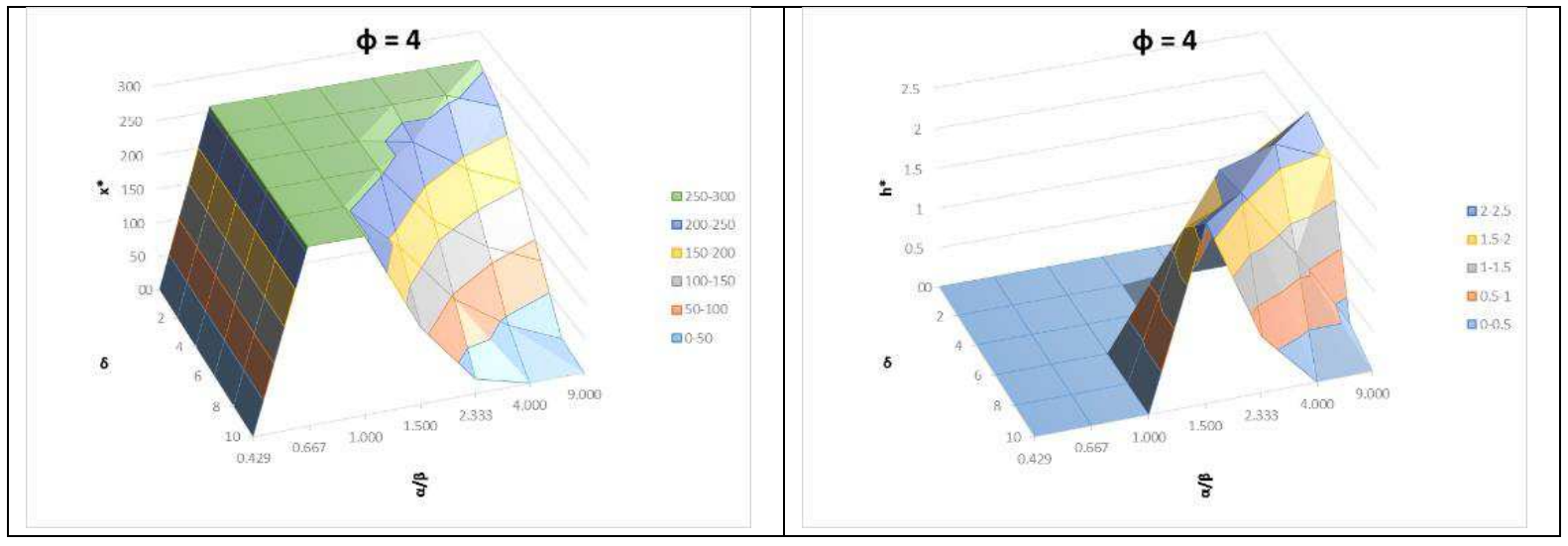

1 Figure 2: Optimal forest stock (in $\mathrm{m}^{3} / \mathrm{acre}$ ) and optimal harvest (in $\mathrm{m}^{3} /$ acre/year) of Southeast Asian 2 forest with LPG as fuelwood substitute, under varied CSV $(\phi), \operatorname{MRS}(\alpha / \beta)$ and discount rates $(\delta)$ 3 scenarios (Continued).

4

5

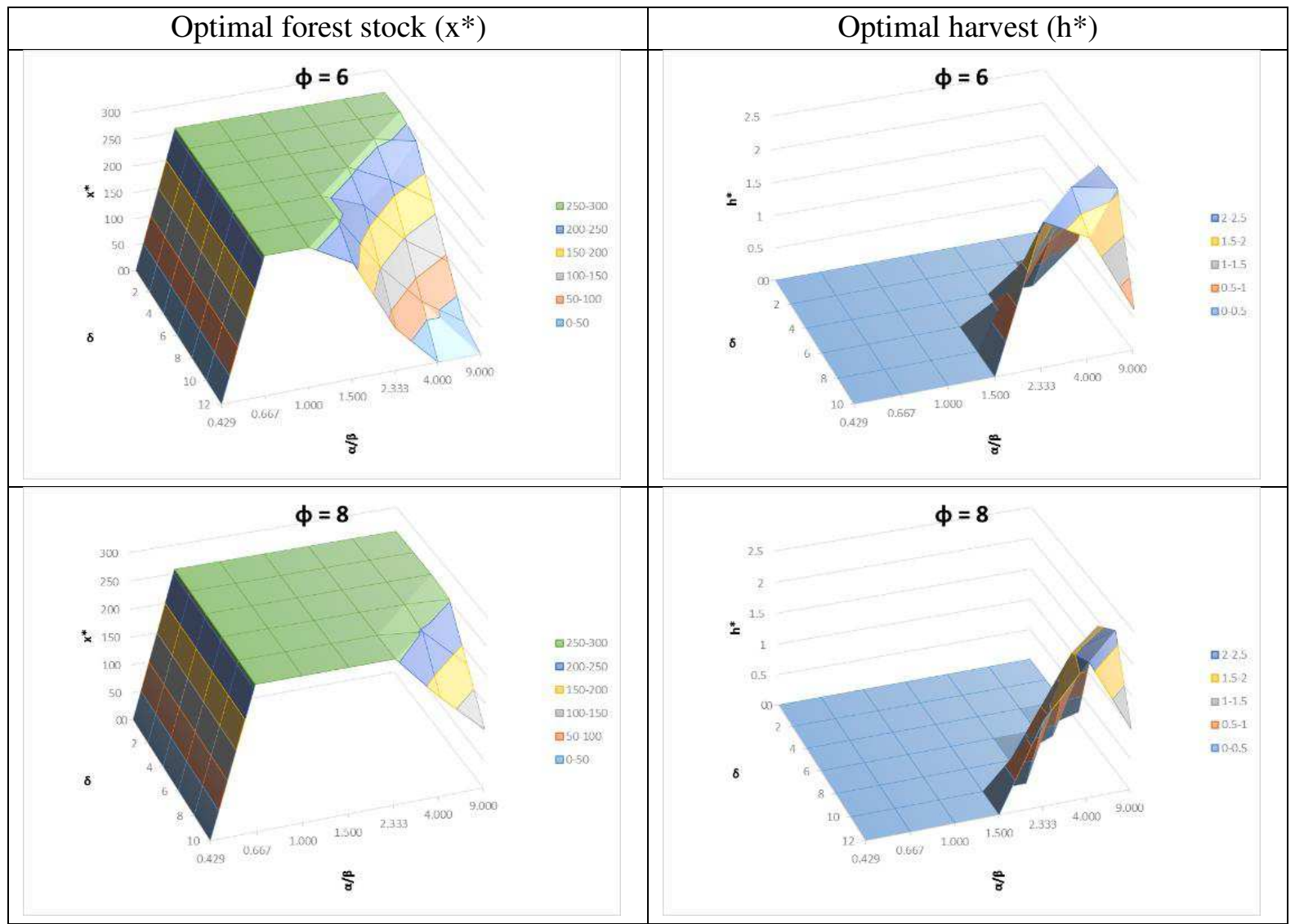




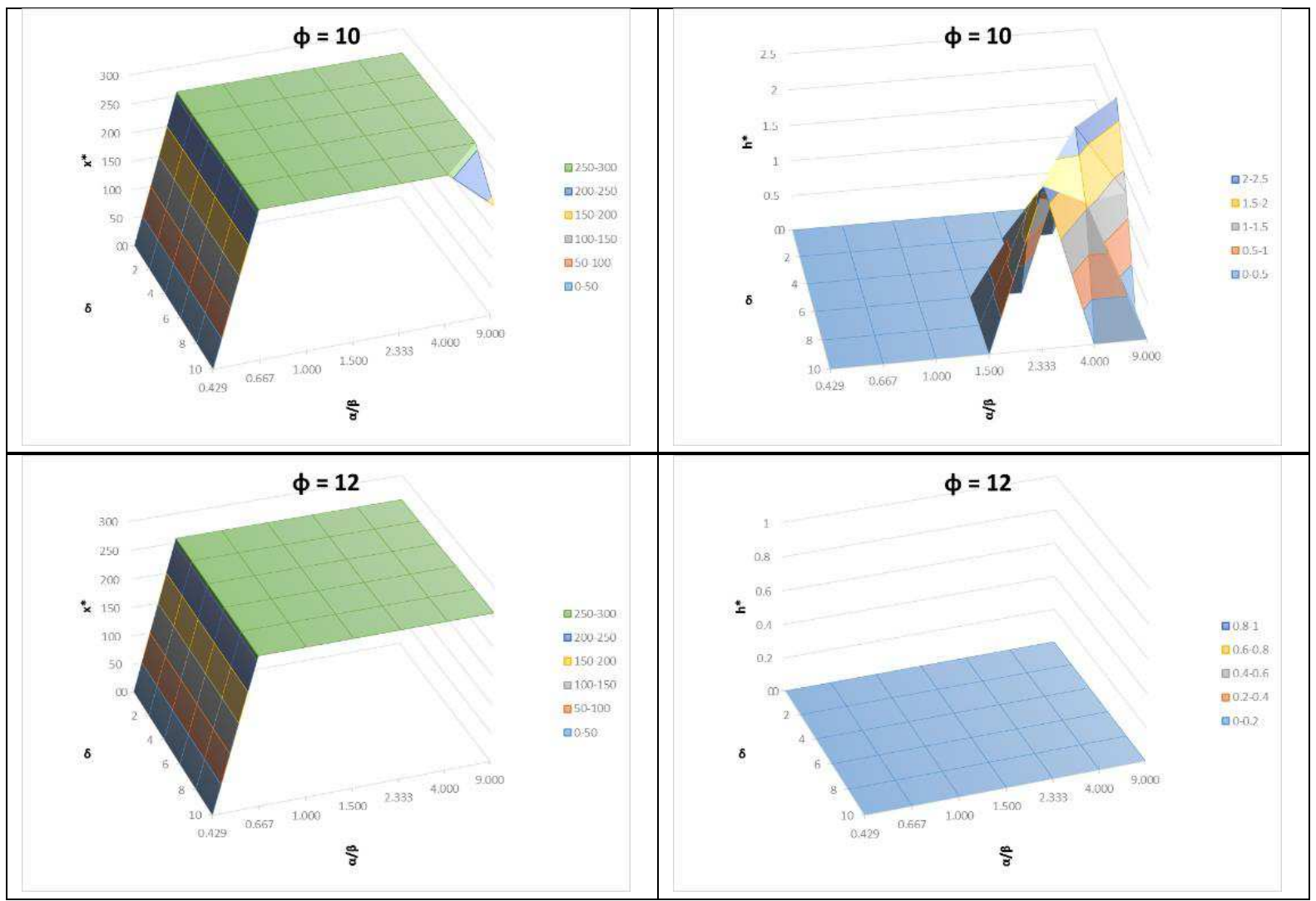

1 Figure 2: (Continued)

2 Figure 2 indicates that in the absence of $\operatorname{CSV}(\varphi=0)$ and zero discount rate, optimal forest stock 3 reaches MSY stock and optimal harvest reaches MSY of the forests. A marginal rise in discount rate, 4 such as $(0<\delta<4)$, triggers rapid fuelwood harvesting at all MRS, leading to clear cutting of the 5 forest. Under conditions where $M R S=\frac{\alpha}{\beta}<\kappa$ leads to $\frac{\varphi}{\alpha-\kappa \beta}<\delta$. This is shown in all cases of non6 zero CSV with $M R S<0.453$. These conditions cause deforestation. The conditions where discount 7 rate is substantially greater than $\frac{\varphi}{\alpha-\kappa \beta}$ leads to a clear cutting of forest. For Conditions where $\frac{\varphi}{\alpha-\kappa \beta}=$ $8 \delta$, it causes optimal forest stock to approach MSY stock. On the other hand, $\frac{\varphi}{\alpha-\kappa \beta}-\delta \geq r$ causes 9 optimal forest stock approach to the carrying capacity and optimal harvest to zero. For instance, with a 10 non-zero CSV and MRS at 0.667 , leads to optimal forest stock reach the carrying capacity of Southeast 11 Asian forest, while optimal harvest to zero. These conditions are prevalent at higher CSV. optimal 12 forest stock and optimal harvest will remain constant for any combination $(\alpha, \beta, \varphi)$ as long as $13\left(\frac{\varphi}{\alpha-\kappa \beta}-\delta\right)$ remain unchanged.

14 Figure 2 indicates that with an increase in CSV, the optimal forest stock is progressively maintained at 15 its carrying capacity, even at a higher MRS and discount rate. At a higher CSV, a high MRS does not 16 lead to decline in the optimal forest stock. Similarly, the effect of a progressive increase in discount rate 17 is nullified by CSV of forest stock and maintains the forest stock at its carrying capacity. On the other 18 hand, at a lower CSV, a combination of high discount rate and high MRS ratio facilitated decline of the 19 forest stock. A CSV of 12 and above, the forest is protected from deforestation. Regarding optimal 20 harvest, an increase in CSV delays the harvest for a higher MRS value. Also, optimal harvest reaches 21 MSY at a still higher MRS with the increase in CSV. A higher discount rate facilitates harvest at a lower 22 MRS. However, a greater CSV deflects the effect of higher discount rate and delays the harvest to a 
2 Figure $3 \mathrm{a}$ and $3 \mathrm{~b}$, gives a cross-section of optimal forest stock and optimal harvest of Southeast Asian 3 forest. Figure 3a indicates that at a fixed discount rate and CSV, a rise in MRS causes a decline in 4 optimal forest stock. In case of optimal harvest, the initial increase in optimal harvest quickly declines 5 due to fall in the optimal forest stock (Figure 3b). An increase in the discount rate, causes a further and 6 steeper decline in optimal forest stock over MRS. A proportionate amount of optimal harvest also 7 increases with the rise in discount rate. Figure 4a, illustrates the effect of discount rate on optimal forest 8 stock. Optimal forest stock declines over discount rate. The effect gets pronounced with the rise in 9 MRS. optimal harvest initially rises over discount rate, followed by a sharp decline due to fall in the 10 optimal forest stock (Figure 4b). A rise in MRS shifts the optimal harvest towards lower discount rate. 11 A rise in CSV promotes higher optimal forest stock and keeps the forest stock close to the carrying 12 capacity (Figure 5a). A rise in discount rate delays this process to a higher CSV. optimal harvest is 13 higher at lower CSV. But with a rise in the discount rate, fuelwood harvest continues at a higher CSV, 14 though at a lower intensity (Figure 5b). 

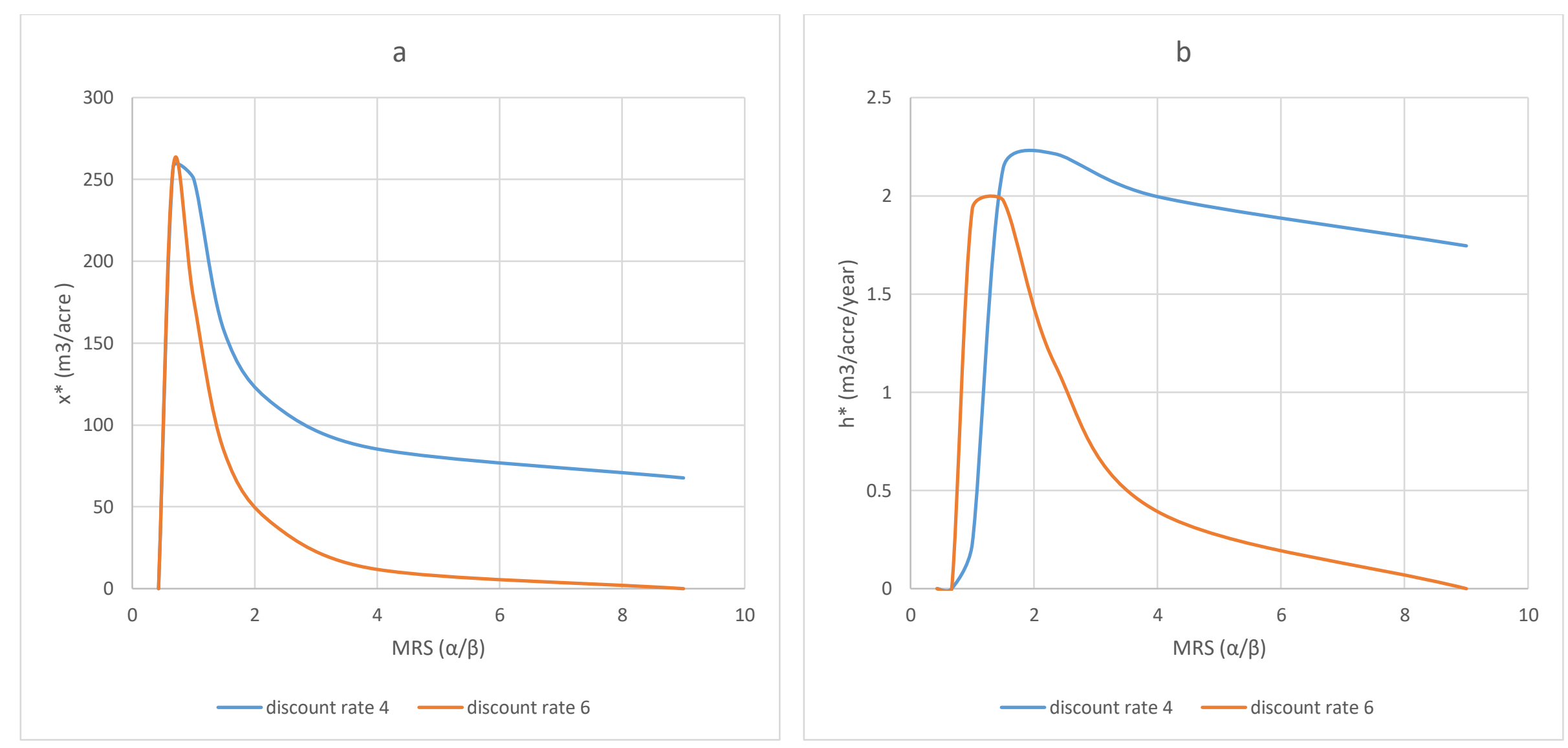

Figure 3: (a) Optimal forest stock and (b) optimal harvest, of Southeast Asian forest over MRS, when discount rate $\delta=4$ and 6, and CSV $\varphi=2$. 

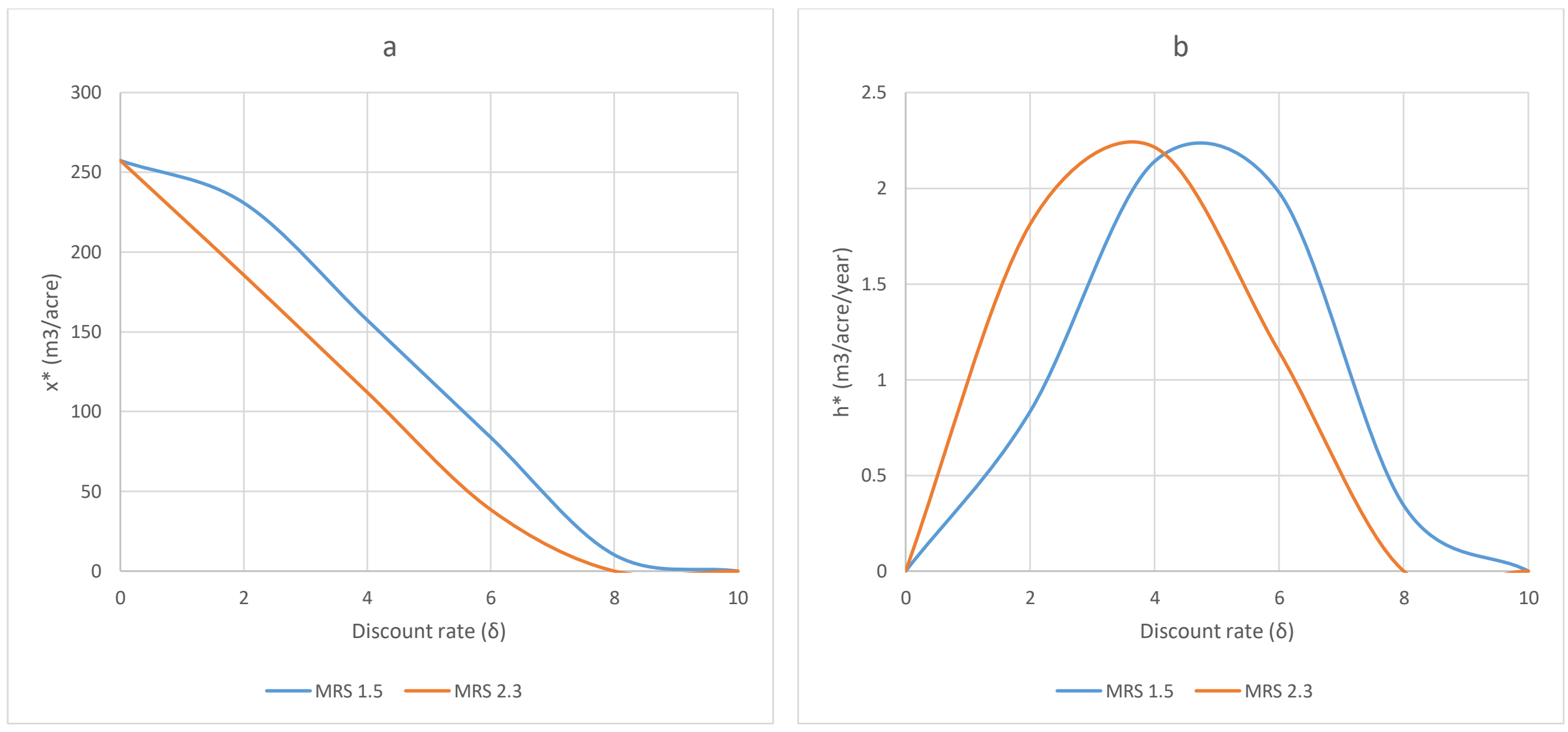

Figure 4: (a) Optimal forest stock and (b) optimal harvest of Southeast Asian forest over discount rate, when MRS $\frac{\alpha}{\beta}=1.5$ and 2.33 , and CSV $\varphi=2$. 


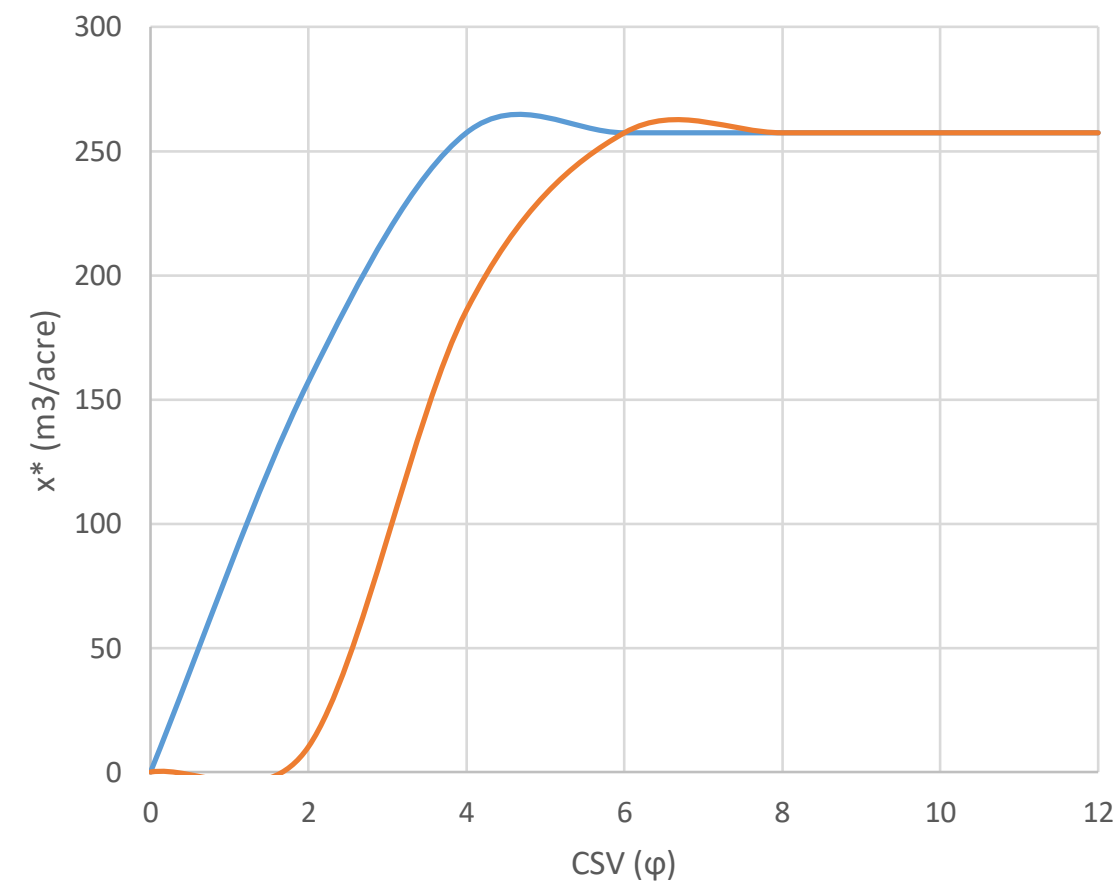

MRS 1.5 and discount rate 4

MRS 1.5 and discount rate 8

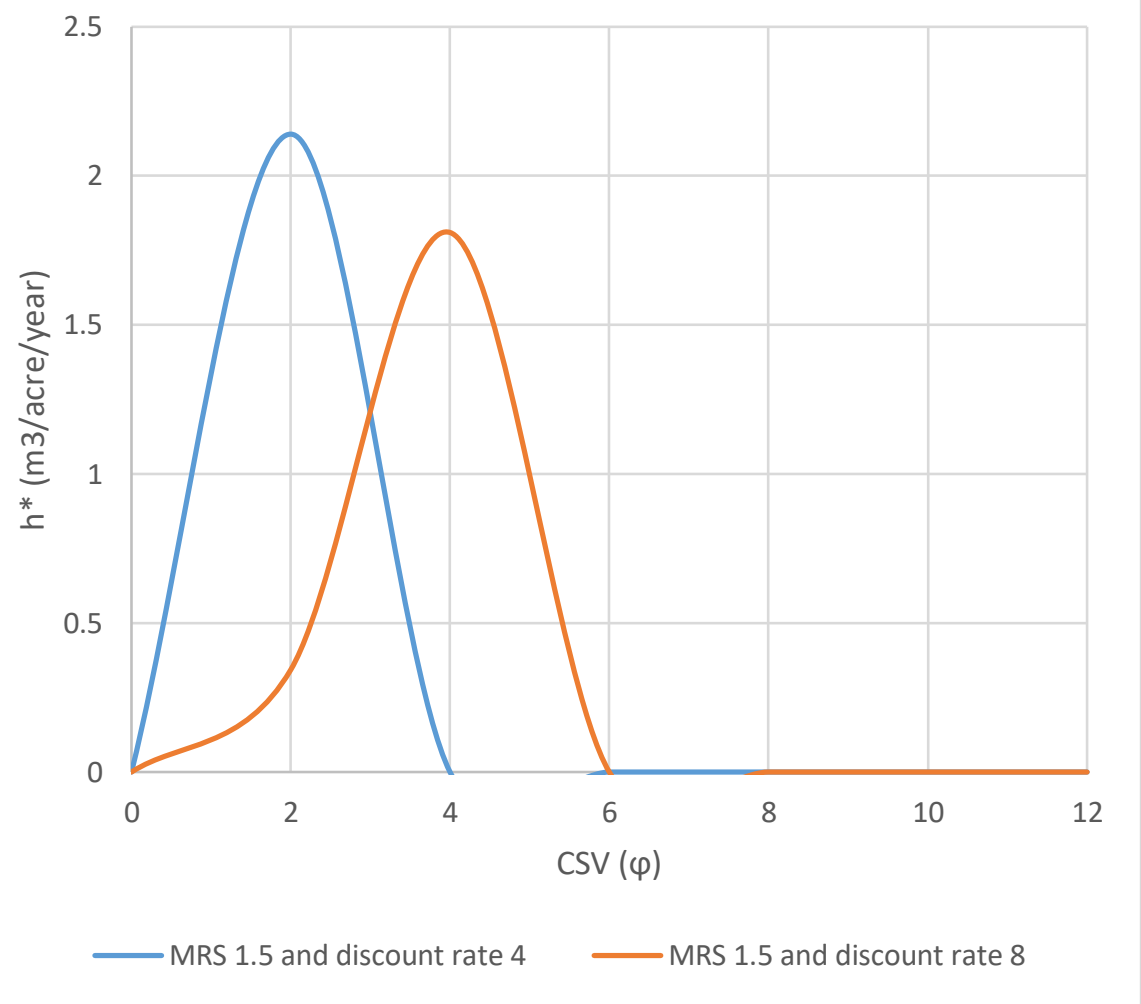

Figure 5: (a) Optimal forest stock and (b) optimal harvest of Southeast Asian forest over CSV, when discount rate $\delta=4$ and 8 , and MRS $\frac{\alpha}{\beta}=1.5$. 


\section{Discussion}

2 Open access natural forests such as the state-owned revenue forests in developing countries play a 3 central role in meeting the basic social and economic needs of the landless and marginal farmers as well 4 as the poor habitants living in the vicinity of forests. Along with low grade timber, these forests provide 5 them with fodder, fuelwood and other forms of non-timber benefits. Excessive population increase and 6 remoteness of such habitations from proper domestic energy amenities have caused over-dependence 7 on fuelwood extraction. Under this scenario, provision of subsidised alternatives to fuelwood like LPG can substantially reduce the dependency on fuelwood and expend the forest from further exploitation.

9 In Gan et al. (2001), effects of discount rate, silvicultural cost, timber benefits and non-timber forest 10 benefits on forest stock, silvicultural effort and harvest were studied. In contrary, the present study assesses the effect of fuelwood substitute, forest values and discount rate on forest stock and biomass harvest in terms of fuelwood extraction. To do this, a theoretical model was constructed to analyse the impact of MRS of fuelwood, discount rate and CSV on the forest stock and level of fuelwood harvest. An empirical example of the Southeast Asian forest and LPG as the fuelwood substitute was used to illustrate the results.

The first order condition of optimal control theory indicated that in the absence of CSV, the fuelwood extraction should be such that the marginal forest growth equals discount rate (Gan et al., 2001). The model showed that the discount rate decreases in the absence of MUF and increase in the absence of MUS. This observation has direct relation with the conservation policy. A low discount rate promotes deforestation while a high discount rate delays deforestation (Bulte \& van Soest, 1996; Greǵe-Staltmane 21 \& Tuherm, 2010).

Marginal growth of the forest was influenced by $\kappa$ value, the ratio of energy per unit of the substitute to that of fuelwood. MRS greater than $\kappa$ promoted fuelwood harvest and led to decline in the marginal growth of the forest. An opposite condition of MRS, lesser than $\kappa$ discouraged fuelwood harvest and maintained greater forest stock. Hence, $\kappa$ value can be considered as a critical value that switches consumer behaviour from exploitation to conservation. Thus while considering fuelwood substitutes the forest managers should consider a substitute that yields greater energy per unit mass to maintain healthy forest stock. Apart from $\kappa$ value, marginal forest growth and harvesting decision were also influenced by the discount rate. Marginal growth in forest stock was negative when discount rate was zero. It was positive when $\frac{V_{x}}{U_{h}-\kappa U_{S}}$ was less than the discount rate. This aspect of relationship between instantaneous forest stock and discount rate needs further studies.

Comparative statics indicated that the optimal forest stock and optimal harvest were sensitive to change in discount rate, MUF, MUS and marginal change in CSV. However, unlike Gan et al. (2001) the determinant of matrix of simultaneous equations, $\boldsymbol{A}$ in this paper was negative. Hence, apart from model variables like fuelwood substitute and CSV, the present model intrinsically deviates from the work of Gan et al. (2001). The marginal rate of change of optimal forest stock to discount rate was negative (Gan et al., 2001). The marginal rate of change of optimal fuelwood harvest to discount rate was positive, zero or negative whenever the forest stock was below, equal to or above the MSY stock respectively. These outcomes indicate that forest stock has critical role to play in the decision of the consumers (Clark, 1990).

41 The marginal rate of change of optimal forest stock to CSV was negative or positive depending on 42 whether the MRS was less than or greater than the $\kappa$ value. This indicates that a low energy-yielding 
1 substitute will promote deforestation even when forest is valued through CSV. On the other hand, a 2 high energy substitute complemented with high CSV will promote forest conservation. There was no 3 solution for marginal rate of change of optimal forest stock to CSV when MRS was equal to the $\kappa$ value. 4 Similarly, the marginal change in optimal harvest to CSV is rather ambiguous. It depended on whether 5 the MRS was greater than, lesser than or equal to the $\kappa$ value and the sign of marginal change of forest 6 stock. Furthermore, there was no solution to the marginal change in the rate of optimal harvest to CSV 7 when MRS was equal to the $\kappa$ value. The unexplained relations of marginal rate of change of optimal 8 forest stock and marginal change in optimal harvest when MRS equals $\kappa$ are probably due to non9 economic exogenous variables (Lee et al., 2015).

10 The marginal rate of change of optimal forest stock to MUF was negative. This indicated that continues 11 fuelwood extraction eroded the forest stock. In contrast, the relationship between forest health and MUF 12 remained ambiguous in the study of Gan et al. (2001). Marginal change of optimal harvest to MUF was 13 positive, zero or negative when forest stock was above, equal to or below the MSY stock. The marginal 14 change in optimal forest stock to MUS was positive. While marginal change of optimal harvest to MUS 15 was negative, zero or positive when forest stock was below, equal to or above the MSY stock.

16 The empirical example of the Southeast Asian forest and LPG as a substitute to fuelwood showed that 17 increase in discount rate led to optimal harvest at a lower value of MRS of fuelwood by LPG. Moreover, 18 the increase in the CSV delays the optimal harvest to a higher value of MRS. The effect of discount rate 19 was offset by increase in CSV. At zero CSV and discount rate, the optimal harvest approached MSY 20 and optimal forest stock approached MSY stock. However, at higher values of discount rate when CSV 21 was not considered, the optimal forest stock quickly declined towards complete clear cutting condition. 22 With the decrease in forest stock and, the harvest also declined. The decline in harvest was further 23 encouraged by a higher discount rate. At a very low MRS, such as 0.434 or below led to clear cut of the 24 forest in all values of discount rate and CSV. A value of MRS between 0.434 and 0.667 led to rapid recovery of the forest stock as the optimal harvest was not viable in all values of discount rate and CSV. However, with MRS being above 0.667 the optimal harvest increased with increase in discount rate and decrease in CSV. The effect of discount rate as well as higher MRS was completely offset by a high CSV of 12 and above. These observations are in harmony with the results of the theoretical model constructed here.

The outcomes of this study are in harmony with field studies. For instance, study in Uganda suggests that forest degradation is more intense due to fuelwood extraction in the absence of suitable substitutes (Sassen, Sheil, \& Giller, 2015). Furthermore, study on the role of improved chulla, a form of cooking oven, on the fuelwood consumption in Chunati Wildlife Sanctuary in Bangladesh by female forest user groups indicated that efficient fuelwood use can reduce dependence on the forest (Roy, 2008). Contrary to this study, other studies indicate subsidised fuel to households may not necessarily prevent deforestation and forest degradation. There can be other non-economic drivers that may negate the effects of fuelwood substitutes (Lee et al., 2015). Considering the importance of forest value, as stated in this study, non-monetary forest values like CSV have positive impacts on forest conservation (Lowman \& Sinu, 2017). In fact, forest conservation policies should include and promote such forest values (Agnoletti \& Santoro, 2015). On the contrary, ignoring such forest values may erode such value systems and promote deforestation (Torres et al., 2016). The model presented in this study theoretically supports the observation of the above studies.

43 The model discussed here is essentially classic and deterministic in nature. Moreover, the analysis is 44 based on the comparative statics of steady state conditions of the forest stock. These conditions were 
adopted for the ease of analysis, at the cost of ignoring the dynamic and stochastic nature of the forest system. Consideration of steady state conditions is appropriate for long term equilibrium and sustainable forestry. However, in many cases, a forest may not be or is not intended to be in steady state condition.

The theoretical model and empirical example as discussed here provide relevant insights into the role of discount rate, CSV and MRS on the optimal forest stock and optimal harvesting of fuelwood. It showed that the MSY stock and ratio of energy values per unit mass of fuelwood to its substitute play a critical role in the fate of forest and level of fuelwood extraction. Furthermore, it was observed that by providing a relevant and subsidised energy option like LPG to the households can substantially reduce fuelwood extraction and maintain the forest stock close to its carrying capacity. Also, high CSV of the forest to the community can significantly reduce exploitation of the forest. Thereby, a state may develop welfare schemes to provide subsidised and better substitutes like LPG, biogas or energy plantation to the forest-dependent communities to protect the forest from further exploitation. Moreover, conservation agencies can encourage the CSV of the forest through festivals and folk culture that promotes forest conservation.

\section{Conclusion}

16 The present study provides certain insights into the relation of fuelwood substitute, CSV and forest conditions. The optimal forest stock and optimal harvest critically depend on the ratio of the energy value of the substitute to that of the fuelwood. In addition to that, level of CSV of the consumers' community and discount rate of the forest have a significant role to play in the fate of a forest. These findings can act as policy interventions towards prevailing forest conservation policies. The model is deterministic and the analysis is static in nature. These limitations can be overcome by introducing stochastic modelling and performing sensitivity analysis. This study can be further extended by analysing the effects of varied substitutes and forest types on the forest stock and harvest decision. Introduction of stochasticity can present a more realistic model. The role of CSV on optimal harvest needs further analysis. Based on these findings, efforts can be made by the government agencies and NGOs to promote subsidised alternatives to fuelwood extracted from the forest. Alternatives like subsidised LPG cylinders, microfinancing of fuelwood producing agroforestry or energy plantation schemes can spare the natural forests from further exploitation. Also, promotion of CSV by upholding the forest-friendly cultural values and conserving the current forest stock can improve the forest regime.

\section{References}

Adhikari, R. (2002). Impact of biogas programme on forest conservation (Institute of Forestry, Pokhara Tribhuvan University, Nepal). Retrieved from https://www.researchgate.net/publication/262675001_Impact_of_biogas_programme_on_fore st_conservation

Agarwala, M., Ghoshal, S., Verchot, L., Martius, C., Ahuja, R., \& DeFries, R. (2017). Impact of biogas interventions on forest biomass and regeneration in southern India. Global Ecology and Conservation, 11, 213-223. https://doi.org/10.1016/j.gecco.2017.06.005

Agnoletti, M., \& Santoro, A. (2015). Cultural values and sustainable forest management: The case of 

Europe. Journal of Forest Research, 20(5), 438-444. https://doi.org/10.1007/s10310-015$0500-7$

Amacher, G., Ollikainen, M., \& Koskela, E. A. (2009). Economics of Forest Resources (1 edition). Cambridge, Mass: The MIT Press.

Bauer, H. (1996). Automotive handbook (4th ed.). Stuttgart: Robert Bosch Gmbtt.

Brown, G., Tolsma, A., Murphy, S., Miehs, A., McNabb, E., \& York, A. (2009). Ecological impacts of firewood collection -a literature review to inform firewood management on public land in Victoria. Melbourne: Victorian Government Department of Sustainability and Environment.

Bulte, E., \& van Soest, D. (1996). A Note on High Discount Rates and Depletion of Primary Forests. Journal of Agricultural and Resource Economics, 21(2), 341-350. Retrieved from JSTOR.

Clark, C. W. (1990). The Mathematical bioeconomics (2nd ed.). Hoboken, New Jersey: John Wiley and Sons.

Daniel, T. C., Muhar, A., Arnberger, A., Aznar, O., Boyd, J. W., Chan, K. M. A., ... von der Dunk, A. (2012). Contributions of cultural services to the ecosystem services agenda. Proceedings of the National Academy of Sciences, 109(23), 8812-8819. https://doi.org/10.1073/pnas.1114773109

Duruaku, J. I., Ajiwe, V. I. E., Okoye, N. H., \& Arinze, R. U. (2016). An Evaluation of the Calorific Values of the Branches and Stems of 11 Tropical Trees. Journal of Sustainable Bioenergy Systems, 06, 44. https://doi.org/10.4236/jsbs.2016.62005

Faustmann, M. (1849). Calculation of value which forest land and immature stand possess. Reprinted in Journal of Forest Economics, 1, 89-114.

Gan, J., Kolison, S. H., \& Colletti, J. P. (2001). Optimal forest stock and harvest with valuing nontimber benefits: A case of US coniferous forests. Forest Policy and Economics, 2(2), $167-$ 178. https://doi.org/10.1016/S1389-9341(01)00051-X

Grege-Staltmane, E., \& Tuherm, H. (2010). Importance of Discount Rate in Latvian Forest Valuation. Baltic Forestry, 16(2), 303-311.

Hartman, R. (1976). The Harvesting Decision Whena Standing Forest Has Valuea. Economic Inquiry, 14(1), 52-58. https://doi.org/10.1111/j.1465-7295.1976.tb00377.x 
1 Heltberg, R., Arndt, T. C., \& Sekhar, N. U. (2000). Fuelwood Consumption and Forest Degradation: A Household Model for Domestic Energy Substitution in Rural India. Land Economics, 76(2), 213-232. https://doi.org/10.2307/3147225

Jagger, P., \& Kittner, N. (2017). Deforestation and biomass fuel dynamics in Uganda. Biomass and Bioenergy, 105, 1-9. https://doi.org/10.1016/j.biombioe.2017.06.005

Joshee, B. R., Amacher, G. S., \& Hyde, W. F. (2000). Household fuelwood production and consumption, substitution and innovation in two districts of Nepal in Economics of forestry and rural development: An empirical introduction from Asia. The University of Michigan press, Michigan.

Kallio, M., Dykstra, D., \& Binkley, C. Z. Ed. (1987). The global forest sector: An analytical perspective. The Global Forest Sector: An Analytical Perspective. Retrieved from https://www.cabdirect.org/cabdirect/abstract/19880621285

Kant, S. (2000). A dynamic approach to forest regimes in developing economies. Ecological Economics, 32(2), 287-300. https://doi.org/10.1016/S0921-8009(99)00100-7

Laird, S. A. (1999). 9. Forests, Culture and Conservation. In Cultural and Spiritual Values of Biodiversity (Vols. 1-0, pp. 345-396). https://doi.org/10.3362/9781780445434.009

Lee, S. M., Kim, Y.-S., Jaung, W., Latifah, S., Afifi, M., \& Fisher, L. A. (2015). Forests, fuelwood and livelihoods-Energy transition patterns in eastern Indonesia. Energy Policy, 85, 61-70. https://doi.org/10.1016/j.enpol.2015.04.030

Lowman, M. D., \& Sinu, P. A. (2017). Can the Spiritual Values of Forests Inspire Effective Conservation? BioScience, 67(8), 688-690. https://doi.org/10.1093/biosci/bix057

Lyon, K. (2004). Modeling Timber Supply, Fuel-Wood, and Atmospheric Carbon Mitigation. Utah State University, Department of Economics, Working Papers. Retrieved from https://www.researchgate.net/publication/23696669_Modeling_Timber_Supply_FuelWood_and_Atmospheric_Carbon_Mitigation

National Sample Survey Organization (NSSO). (2012). Energy sources of Indian households for cooking and lighting (NSS 66th Round, July 2009- June 2010 No. Report No. 542 (66/1.0/4)). New Delhi: National Sample Survey Office, Ministry of Statistics and Programme 
Implementation.

2 Pandey, D. (2002). Fuelwood Studies in India: Myth and Reality. Retrieved from Center for International Forestry Research website: https://www.jstor.org/stable/resrep02013

Pattanayak, S. K., Sills, E. O., \& Kramer, R. A. (2004). Seeing the forest for the fuel. Environment and Development Economics, 9(2), 155-179. https://doi.org/10.1017/S1355770X03001220

Ranjan, R. (2018). What drives forest degradation in the central Himalayas? Understanding the feedback dynamics between participatory forest management institutions and the species composition of forests. Forest Policy and Economics, 95, 85-101. https://doi.org/10.1016/j.forpol.2018.07.010

Robinson, E. J. Z., Albers, H. J., \& Williams, J. C. (2008). Spatial and temporal modeling of community non-timber forest extraction. Journal of Environmental Economics and Management, 56(3), 234-245. https://doi.org/10.1016/j.jeem.2008.04.002

Roy, B. C. S. (2008). Connecting communities and conservation: Collaborative management of protected areas in Bangladesh. In Fuelwood, alternative energy and forest user groups in Chunati Wildlife Sanctuary. Retrieved from https://www.researchgate.net/publication/303079164_Connecting_Communities_and_Conser vation_Comanagement_Initiatives_Implemented_by_IPAC_in_Wetlands_and_Forests_of_Bangladesh

Sassen, M., Sheil, D., \& Giller, K. E. (2015). Fuelwood collection and its impacts on a protected tropical mountain forest in Uganda. Forest Ecology and Management, 354, 56-67. https://doi.org/10.1016/j.foreco.2015.06.037

Spîrchez, C., Lunguleasa, A., \& Croitoru, C. (2017). The importance of the wood biomass in environment protection. AIP Conference Proceedings, 1918(1), 020007. https://doi.org/10.1063/1.5018502

Thierry Lefevre, Jessie L. Todoc, G. R. T. (1997). Implications for the forestry sector, conclusions and recommendations. In M. A. Trossero, F. Department, F. Nations, A. O. of the United, \& I. Rome (Eds.), The role of wood energy in Asia. Retrieved from http://www.fao.org/docrep/W7519E/W7519e00.htm\#Contents 
1 Torres, P. C., Morsello, C., Parry, L., \& Pardini, R. (2016). Who Cares about Forests and Why?

2

Additional information

\section{Contributions}

10 The author contributed to the conceptualization, construction, analysis and interpretation of the model.

\section{Competing interests}

12 The author(s) declare no competing interests. 
Figures

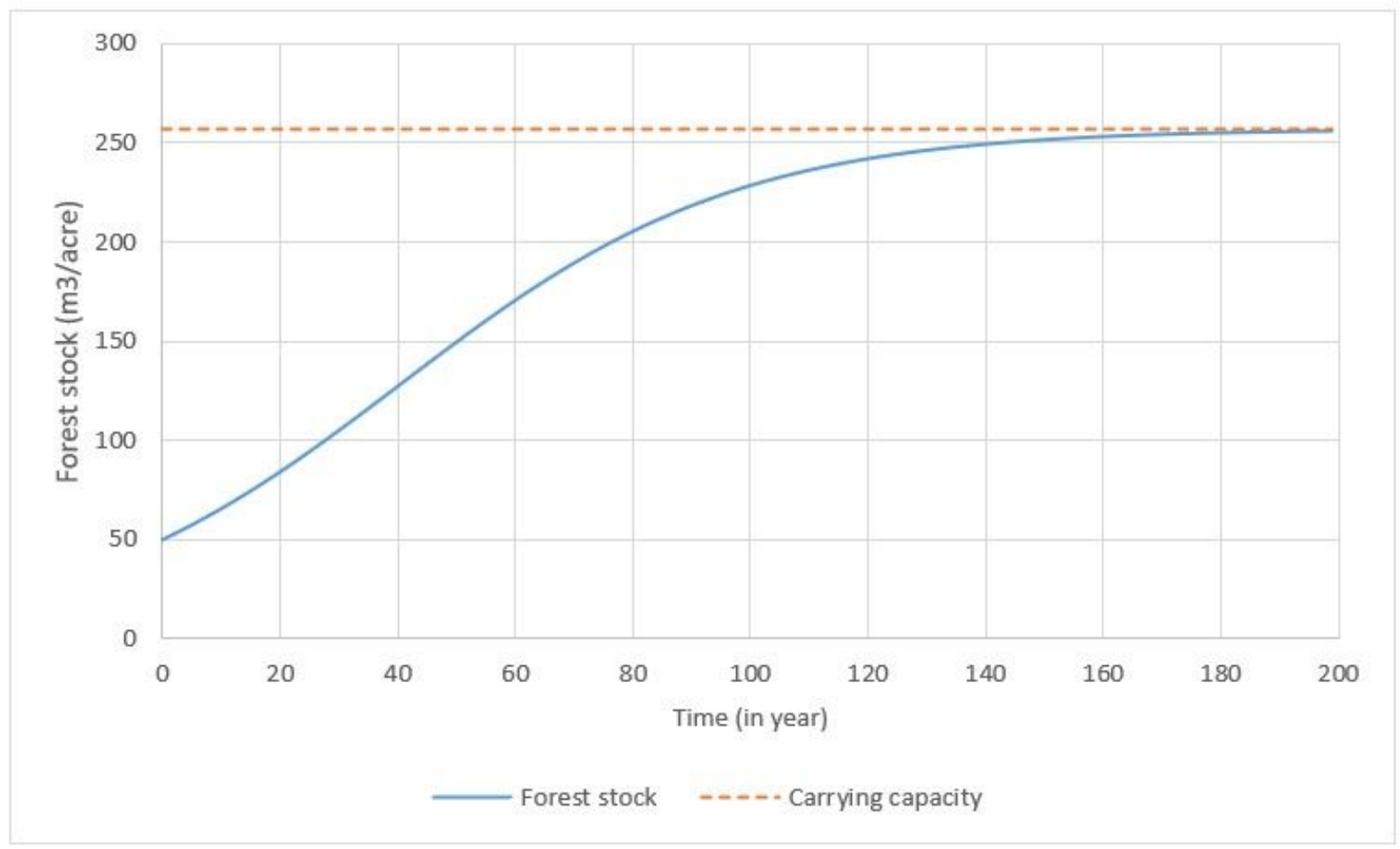

\section{Figure 1}

Due to technical limitations, the figure legends are available in the supplementary section. 


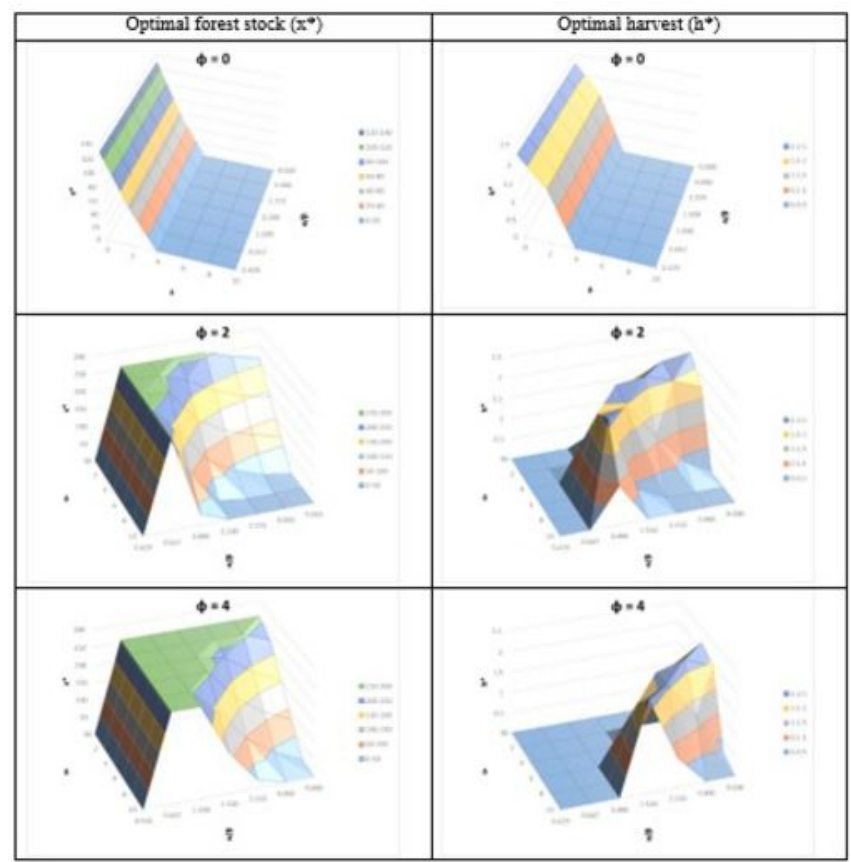

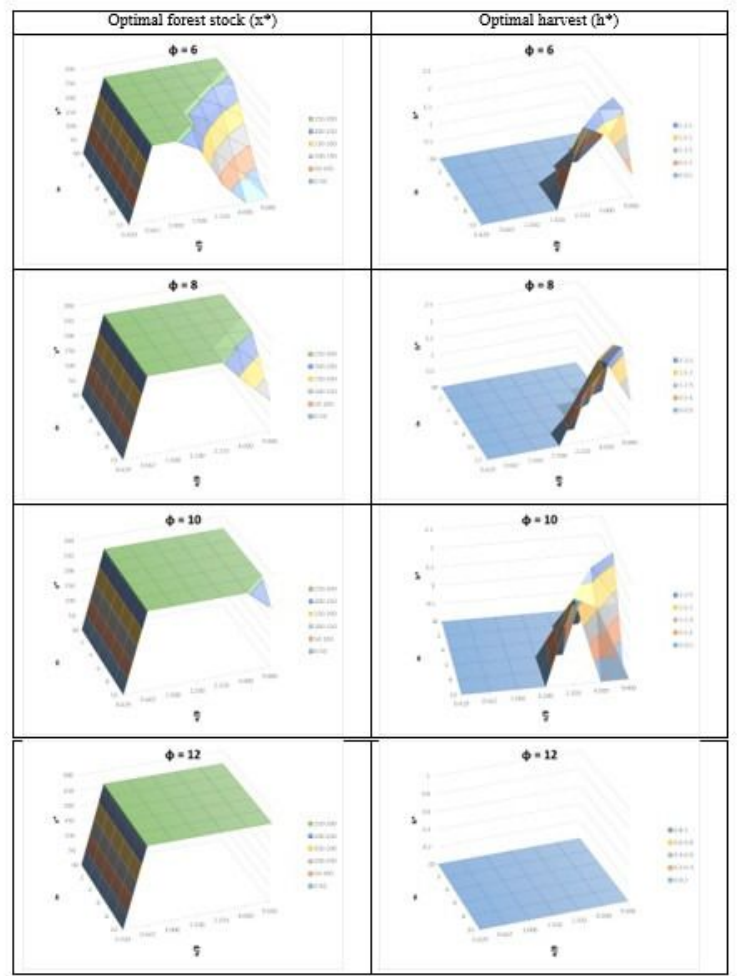

Figure 2

Due to technical limitations, the figure legends are available in the supplementary section.
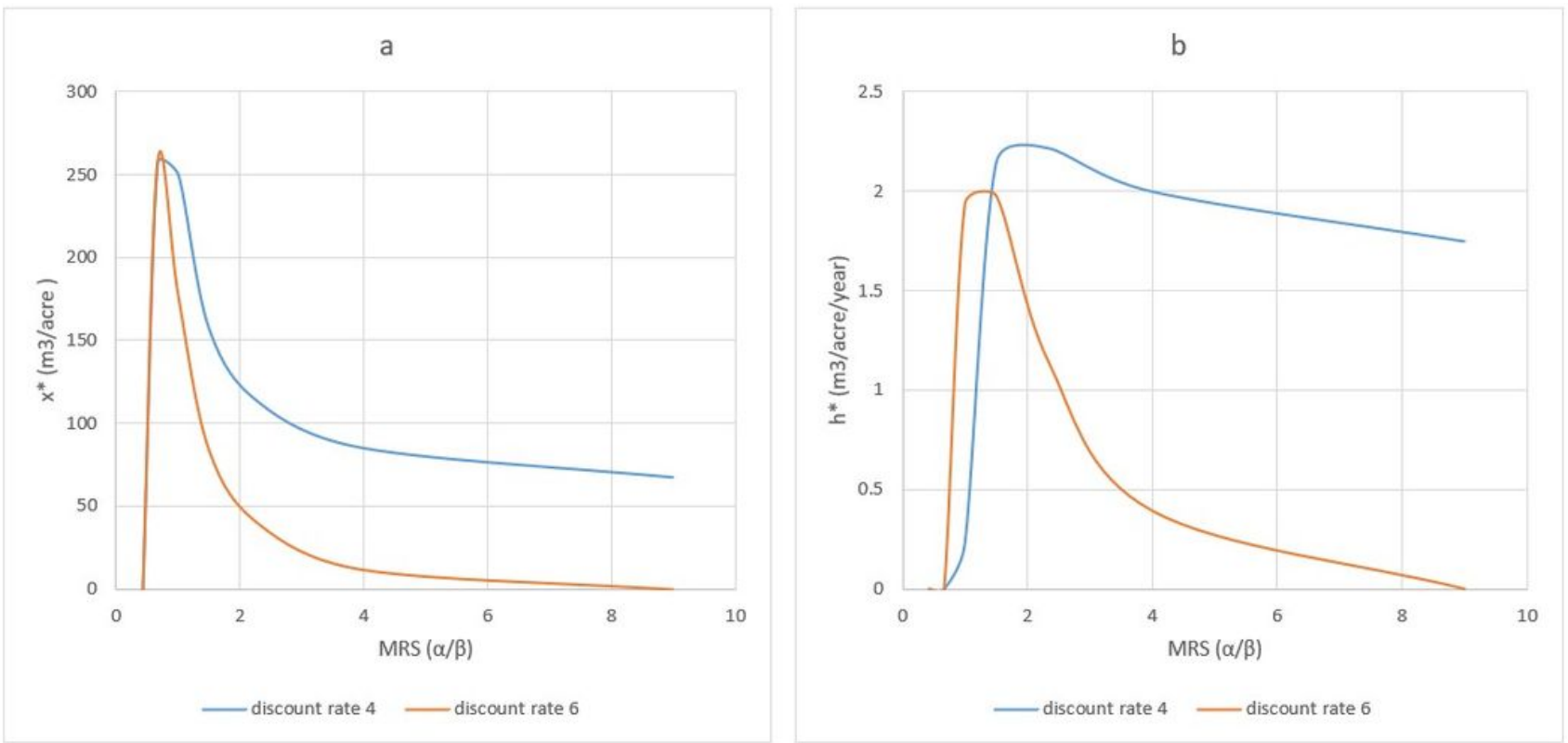

Figure 3

Due to technical limitations, the figure legends are available in the supplementary section. 

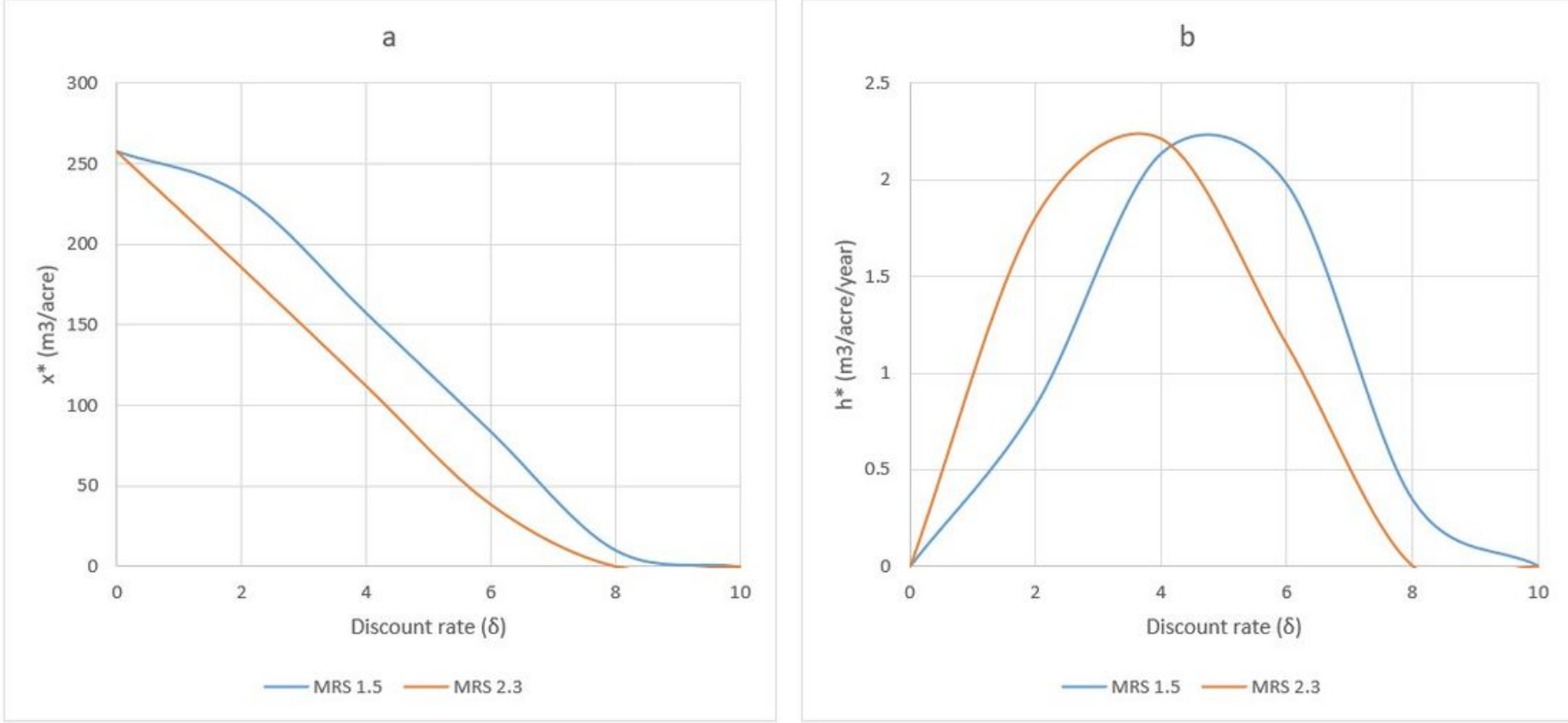

Figure 4

Due to technical limitations, the figure legends are available in the supplementary section.
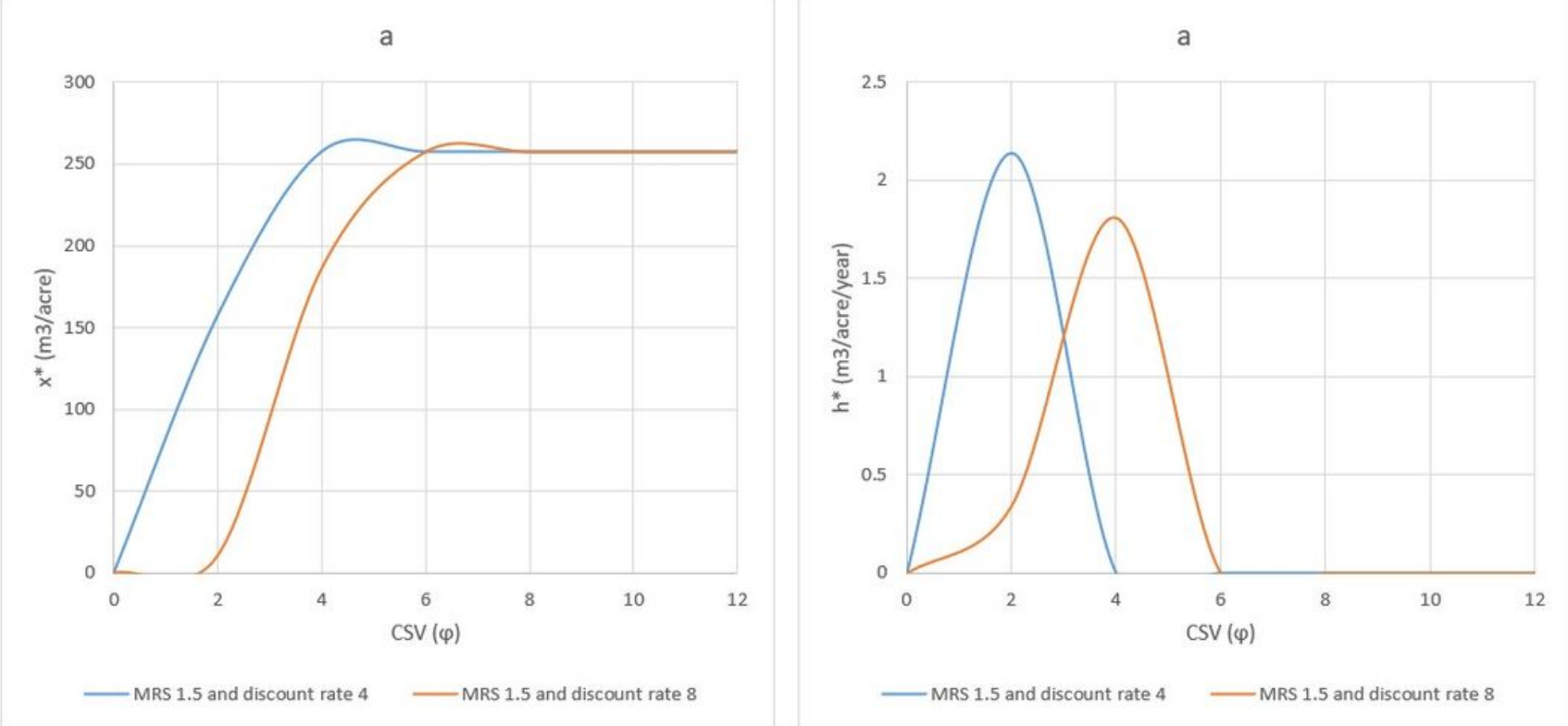

\section{Figure 5}

Due to technical limitations, the figure legends are available in the supplementary section.

\section{Supplementary Files}


This is a list of supplementary files associated with this preprint. Click to download.

- Supplementanddataset.docx

- Figurelegends.docx 